\title{
Temporal pattern analysis of voicing in children with and without alterations in sonority feature
}

Liliane Ramone ${ }^{1}$
https://orcid.org/0000-0002-0368-2495

Silvana de Coelho Frota ${ }^{1}$ https://orcid.org/0000-0003-3439-9681

${ }^{1}$ Universidade Federal do Rio de Janeiro, Rio de Janeiro, Rio de Janeiro, Brasil.

Research support source: Conselho Nacional de Desenvolvimento Científico e Tecnológico - CNPQ.

Conflict of interests: Nonexistent

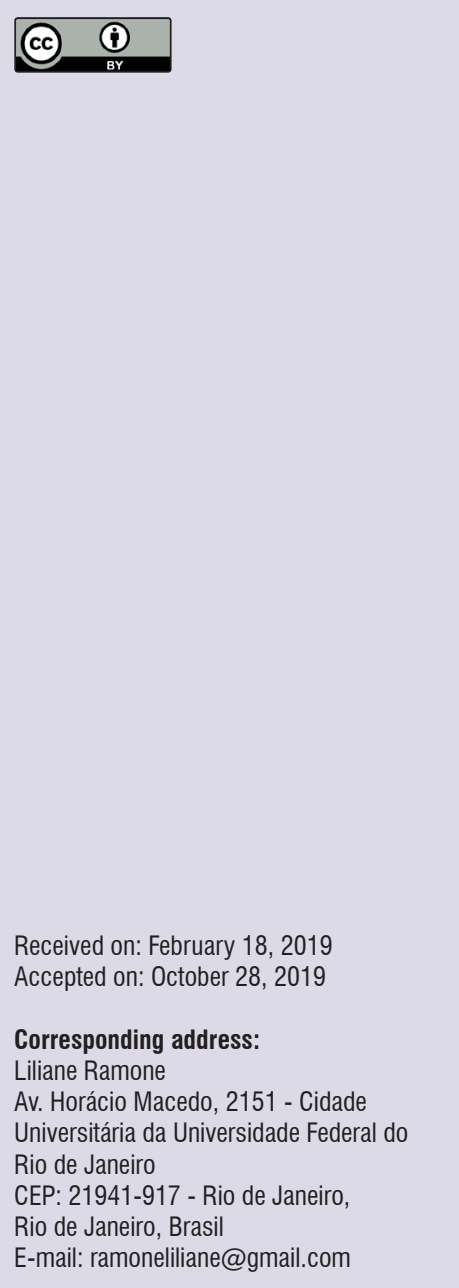

\section{ABSTRACT}

Purpose: to compare acoustic characteristics of stop consonants in speakers of Brazilian Portuguese with and without alterations in speech referring to voicing feature.

Methods: out of 66 children assessed, 18 were selected for this study, aged from 9 to 12 years, distributed in Control Group, 8 without language alterations, and Deviation Group, 10 children with alterations in speech, regarding sonority features. Participants with hearing loss, with cognitive deficit, left-handed ones or using neurological medication, were excluded. The following tests were performed: tonal audiometry, ABFW speech test, and a PowerPoint interactive production test, which was developed by the author for this study, with the purpose of comparing the minimal pairs in words. At the end, the acoustic analysis was conducted, by using the PRAAT program. The acoustic characteristics of stops related to total and relative duration of voice onset time were compared in the two groups and analyzed by the Mann-Whitney $U$ test, with a significance level lower than 0.05 .

Results: significant differences were observed in the duration of the voice onset time between the two groups, such as the increase in absolute voice onset time in the Deviation Group in voiced stops, and reduction in absolute onset time in voiceless stops. The relative voice onset time presented significant differences between the two groups only in voiceless stops.

Conclusion: Brazilian Portuguese speakers with alteration in their sonority feature showed an acoustic pattern different from that of other speakers, regarding the voice onset time.

Keywords: Acoustics; Speech, Language and Hearing Sciences; Language 


\section{INTRODUCTION}

Voicing feature is almost universal, though with nuances among the languages. Researches involving babies point to the capacity of categorical perception of voicing feature marks in the first months of life ${ }^{1-4}$. For this reason, voicing feature has been widely approached in studies on acquisition of, and deviations from the language $e^{4,5}$. The main question is: Why do some children not reach the correct pattern of voicing contrast after the period of language acquisition, and shift voiced and voiceless phonemes?

It is important to highlight that the cues or acoustic correlates of voicing vary from language to language. Therefore, the perception of a phoneme is not tied to absolute values that correspond to acoustic information, but to variations in value ranges, i.e., the categories. In the case of perceiving voicing features, variations in voice onset time (VOT) ${ }^{6}$ value ranges promote the distinction of phonemes $/ \mathrm{p} /$ and $/ \mathrm{b} /$, for example. In voicing contrast, the VOT is the most important acoustic information to differ words such as pin/bin in English².

In addition to the VOT, the duration of the stop consonants has been seen as a supplementary indicator to distinguish voicing from non-voicing, as the duration of voiceless stop consonants are longer than that of the voiced ones ${ }^{7-9}$. In English, at the end of the syllable, the voiceless stop consonant is longer than the corresponding voiced one ${ }^{9}$. The initial burst spectrum is considered a secondary voicing cue in labial and coronal consonants, the burst in the voiceless being longer than in the voiced ones ${ }^{9,10}$.

In Brazilian Portuguese (BP), a great part of the papers aiming to establish acoustic patterns related to voicing features were conducted with adult speakers. The justification for the reduced number of studies in children seems to be in the absence of a parameter to measure the vocal tract and the subglottal region, once in the child the structures involved in sound production undergoes modifications along with the gradual osseomuscular growth. The reduced size of the children's vocal tract in relation to the adult's has already been pointed out as a hindrance for the production of voicing ${ }^{11}$. Some papers suggest the existence of child acoustic patterns in $\mathrm{BP}^{7,12-14}$.

Considering the acoustic characteristics, voicing can be a mark in distinguishing consonants. The voiced stop consonants are normally characterized by observable alterations in the formants at the beginning of the vowel subsequent to the voiced stops ${ }^{9}$. As for the voiceless ones, these are characterized by a period of aspiration anterior to the following vowel, called delay, which may vary from language to language. Hence, on the spectrogram, the aspiration is marked by the absence of energy of the first formant $(\mathrm{F} 1)$ and by the absence of voicing regular vertical stretches. In this case, after the burst, there is a brief interval until the beginning of the following vowel. The presence or absence of the voicing bar is also an acoustic mark that distinguishes the stops regarding voicing ${ }^{9}$. In the voiced stops, the voicing bar is visible in the form of vertical stretches at the base of the spectrogram, which corresponds to the vibration of the vocal folds.

The voicing contrast of the BP was analyzed in speakers with and without speech alteration in a project counting with seven speakers with Normal Phonological Development (NPD), and 11 with Phonological Deviation (PD), characterized by alterations in voicing contrast, aged from six to 14 years ${ }^{15}$. Four studies were developed: the duration of the oral vocalic phonemes preceding voiced and voiceless phonemes; the duration of the fricative phonemes in stressed syllables; the VOT of the stop phonemes; and, the investigation of the velar contrast. The results demonstrated disparate values in both groups studied. The author proves the increase in duration of the segment analyzed in the deviation group. The VOT study was conducted in a tonic context, considering the preceding vowel variable. Statistical differences demonstrated the increase of VOT of voiced stops in all vocalic contexts in the deviation group. This did not occur with voiceless stops. The author considers that the children with PD make use of VOT prolongation to differentiate the articulatory gesture between voiced and voiceless phonemes ${ }^{15}$.

Another study with children with PD aged from four to eight years aimed at verifying the occurrence of stop and plosive phoneme desonorization within the Phonological Deviation condition ${ }^{16}$. The variables approached were: most affected phonemes, seriousness of the deviation, and age when affected. Fifty medical records of patients at the Universidade Federal de Santa Maria were analyzed in four age groups. One of the inclusion criteria was that the participant had at least $40 \%$ desonorization in at least one minimal pair. The results confirm the high incidence of desonorization in the Phonological Deviations, in which the stop phonemes have a higher incidence in relation to fricatives. 
The acoustic characteristics of stops in children with Typical Phonological Development and with Phonological Deviation were assessed, presenting alterations in voicing feature ${ }^{17}$. The participants were children between five and seven years old, of whom 11 had Typical Phonological Development, and five had Phonological Deviation. The results, as well as in previous studies, proved the difference of acoustic patterns in both groups investigated. The results obtained in the control group evidenced both the VOT and the vowel adjacent to the stop as distinctive voicing mark, and indicated the measurement of the VOT in voice stops greater than in voiceless ones, and the vowel following the voiced stop longer than the vowel following the silent stop. Comparing the deviation and the control groups, statistically significant values were made evident in the differences of the measurements of the VOT in voiced phonemes, as well as in their occlusion measurement. Nonetheless, this difference was not observed when the measurement was taken in voiceless phonemes. Neither the duration of the vowel nor the amplitude of the burst demonstrated relevant differences. Based on such results, the authors inferred that the duration of the following vowel and the amplitude of the burst are secondary acoustic cues to mark voicing in the segment. The authors also point out to the difficulties in producing the prevoicing, i.e., of the negative VOT in voiced phonemes, and correlates the difficulties to the lack of coordination of the glottal and supraglottal gestures in the interval necessary to produce the voicing ${ }^{17}$.

It is noticed that the VOT measurement seems to be one of the most used parameter in verifying voicing contrast, followed by vocalic context of the segment analyzed, and presence of voicing bar. The relative VOT considers the subject's utterance rate, i.e., the speech speed. Based on acoustic patterns of children six, eight, 10 and 12 years old, significant differences were noted between absolute and relative VOT measurements in the same subject ${ }^{14}$. The author observed that the utterance rate increases with the age group, and attributes such finding to the maturation of the motor speech system.

This study aims at comparing acoustic characteristics of stop consonants in speakers with and without alterations in speech regarding the sonority feature. It is believed that the results of this investigation can contribute to studies concerning the language acquisition and development pattern, in addition to supporting future therapeutic and preventive proposals for the treatment of individuals with shifts related to the sonority feature.

\section{METHODS}

This study was conducted in partnership with the following labs: ACESIN - Laboratório de Acesso Sintático, Laboratório de Fonética Acústica and with the Ambulatório de Exames Complementares do curso de Fonoaudiologia, all belonging to the Universidade Federal do Rio de Janeiro. This research was appraised and approved by the Research Ethics Committee of the Instituto de Neurologia Deolindo Couto (INDC) da Universidade Federal do Rio de Janeiro under number 04235312.0 .0000 .5261 . The participants, as well as the ones responsible for them, were aware and informed about the procedures of the research. The consent was given through the signing of the Informed Consent Form (ICF). Initially, 66 children, students from public schools of Rio de Janeiro, participated in this study. The inclusion criteria adopted were: age range from 9 to 12 years, laterality (right-handed), and absence of cognitive deficits and use of neurologic medication. Such participants were excluded who were left-handed, diagnosed with cognitive deficit, with hearing loss, or with multiple shifts in speech.

Firstly, the ABFW ${ }^{18}$ speech test was applied with the purpose of choosing the children with and without shifts in the sonority feature. Shifts in at least one minimal pair $(/ \mathrm{v} / \mathrm{x} / \mathrm{f} /)$ were accepted, in either direction (desonorization or improper sonorization). The test consists in presenting figures to be named. Based on the application of the test, 23 participants were selected for the research, and classified in two groups: eight children without shifts in their speech - control group (CG), and 15 children with shifts in speech regarding the sonority feature - deviation group (DG). The children were tested in their school of origin. Once the participants had been selected, five children were excluded from the DG for presenting multiple shifts, or for refusing to continue in the research. Thus, 18 participants were selected for the study. Afterwards, the tonal audiometry was performed with the purpose of verifying the integrity of the peripheral auditory system.

After the groups had been selected, in an acoustically prepared room, the Production Test (evoking), created as integral part of the author's ${ }^{19}$ doctoral training, was conducted. The task consisted of evoking the name of the figure in frame phrase. The figures were presented on PowerPoint slides, on which a figure was seen and, underneath it, the frame phrase with a gap 
for evoking: "Ela disse (She said) " (target word), twice. A 14-inch DELL computer was used to present the slides, together withONE of Apogee ${ }^{\circledR}$ as external microphone, and another portable Macintosh computer with the computing programGarageBand (Macintosh, version 6.0.5) to pick up the child's speech. The participants were positioned at a distance of approximately $40 \mathrm{~cm}$ from the computer screen.
The figures had been drawn from a word board with 27 minimal pairs, which were nouns containing stops in the tonicity positions (tonic, pretonic and postonic) and in the three articulation points (bilabial, alveolar, velar). The figures were randomized with the help of the Random Sequence Generator ${ }^{20}$ program, creating seven different presentations of the same test.

Figure 1 demonstrates the list of words used in this paper.

\begin{tabular}{|c|c|c|c|}
\hline Phonemes & Tonic & Pretonic & Postonic \\
\hline$/ \mathrm{p} / \mathrm{x} / \mathrm{b} /$ & panda-banda & potinho-botinho & trompa-tromba \\
\hline & pomba-bomba & picada-bicada & qupa-taba \\
\hline$/ \mathrm{t} / \mathrm{x} / \mathrm{d} /$ & tia-dia & tintinha-dindinha & gato-gado \\
\hline & tênis-Dênis & coleira-goleira & vaca-vaga \\
\hline$/ \mathrm{k} / \mathrm{x} / \mathrm{g} /$ & calo-galo & cordão-gordão & farinha-varinha \\
\hline & cola-gola & faqueiro-vaqueiro & preço-preso \\
\hline$/ \mathrm{f} / \mathrm{x} / \mathrm{v} /$ & faca-vaca & & doce-doze \\
\hline & foto-voto & & queixo-queijo \\
\hline
\end{tabular}

Figure 1. List of words from the stimuli

The audio files were recorded with the .band extension, and posteriorly the target word was clipped for inspection of the phoneme, and analyzed in the PRAAT acoustic analysis software. The measurements of the VOT total and relative duration of voiced and voiceless stops were compared in the control and deviation groups. The voicing was analyzed in stops with different articulation and tonicity points ${ }^{7,14,15}$. The VOT duration measurement followed Lisker and Abramson ${ }^{6}$ convention. Hence, The VOT measurement of the voiced stops was taken in ms of the space between the end of the previous vowel (end of the darker vertical stretches on the spectrogram) and the burst (including it), whose values were negative. The VOT measurement of the voiceless stops was obtained measuring the space between the burst (including it) and the beginning of vocalization of the following vowel (level of the second formant). In this case, usually there is a delay between the burst and the beginning of the following vowel. Once the burst is considered the starting point, consequently the numerical values were positive.

In order to increase trustworthiness of the findings, diminishing the influence of utterance rate, VOT relative duration was measured according to the formula ${ }^{7,14,21}$ :

Relative duration $=$ duration of the stop / duration of the target word $\times 100$.

The data were analyzed through the Mann-Whitney $U$ test, with level of significance lower than 0.05 . The median was used as a comparison measurement for the analysis of the two groups. 


\section{RESULTS}

The ABFW test indicated 14 participants who had shifts in their speech regarding the sonority feature. Of this sample, four participants were excluded for presenting other associated shifts. From that point, the participants were selected for the control group (without alterations - eight children) and the deviation group (with shifts in sonority feature - 10 children).
The duration of VOT was compared between the CG and the DG in voiced and voiceless stops. The following tables demonstrate the VOT values in $\mathrm{ms}$ in the control and deviation groups. In the voiced stops, the numerical value is negative, whereas in the voiceless stops the numerical value is positive. Table 1 displays the VOT values of voiced and voiceless pretonic stops, comparing $C G$ and $D G$.

Table 1. Voice Onset Time (VOT) values in pretonic voiced and voiceless stops in Control Group and Deviation Group

\begin{tabular}{ccccccc}
\hline $\begin{array}{c}\text { Articulation } \\
\text { point }\end{array}$ & \multicolumn{3}{c}{ voiced } & \multicolumn{3}{c}{ voiceless } \\
\cline { 2 - 7 } CG & BLS & VLS & AVERAGE & BLS & VLS & AVERAGE \\
DG & -84.9 & -75.9 & -80.3 & 14 & 40 & 24.5 \\
P-value & $0.034^{*}$ & -112.8 & -119.5 & 16 & 30 & 19.5 \\
\hline
\end{tabular}

Legend: $\mathrm{CG}=$ control group; $\mathrm{DG}=$ deviation group; $\mathrm{BLS}=$ bilabial stop; VLS = velar stop; AVERAGE = average of values between stops; VOT in ms; significant $p$-value $<0.05(5 \%)$ Mann-Whitney U Test and confidence interval for the median.

Table 2 shows the VOT values for the voiced and voiceless tonic stops, comparing CG and DG.
Table 3 shows the VOT values for the voiced and voiceless postonic stops, comparing $C G$ and $D G$.

Table 2. Voice Onset Time (VOT) values in tonic voiced and voiceless stops in Control Group and Deviation Group

\begin{tabular}{ccccccccc}
\hline $\begin{array}{c}\text { Articulation } \\
\text { point }\end{array}$ & \multicolumn{4}{c}{ voiced } & \multicolumn{4}{c}{ voiceless } \\
\cline { 2 - 9 } CG & -116.5 & -105.5 & -83 & -104 & 20 & 24.5 & 45.5 & 26.5 \\
DG & -144.5 & -147 & -111 & -126 & 12 & 15.5 & 33.5 & 17.5 \\
P-value & 0.197 & 0.078 & $0.038^{*}$ & $0.010^{*}$ & 0.051 & 0.456 & $0.035^{\star}$ & $0.036^{*}$ \\
\hline
\end{tabular}

Legend: $C G$ = control group; $D G=$ deviation group; $B L S=$ bilabial stop; $A S=$ alveolar stop; VLS = velar stop; AVERAGE = average of values between stops; VOT in ms; significant p-value $<0.05$ (5\%) Mann-Whitney U Test and confidence interval for the median.

Table 3. Voice Onset Time (VOT) values in postonic voiced and voiceless stops in Control Group and Deviation Group

\begin{tabular}{ccccccccc}
\hline Articulation & \multicolumn{9}{c}{ voiced } & \multicolumn{4}{c}{ voiceless } \\
point & BLS & AS & VLS & AVERAGE & BLS & AS & VLS & AVERAGE \\
\hline CG & -52 & -58.5 & -47 & -51 & 16 & 32 & 36 & 28 \\
DG & -54.5 & -69 & -69 & -65.5 & 16 & 18 & 25.5 & 20 \\
P-value & 0.316 & 0.589 & $0.014^{*}$ & $0.033^{*}$ & 0.528 & 0.327 & 0.165 & 0.060 \\
\hline
\end{tabular}

Legend: $\mathrm{CG}=$ control group; $\mathrm{DG}=$ deviation group; $\mathrm{BLS}=$ bilabial stop; $\mathrm{AS}=$ alveolar stop; VLS = velar stop; AVERAGE = average of values between stops; VOT in ms; significant p-value $<0.05$ (5\%) Mann-Whitney U Test and confidence interval for the median. 
The VOT relative duration was equally compared in the control and deviation groups, and the results are on the following tables. Table 4 displays the relative VOT values for the voiced and voiceless pretonic stops, comparing the $C G$ and $D G$.
The relative VOT values for the voiced and voiceless tonic stops, comparing the $C G$ and $D G$ is shown in Table 5.

Table 6 shows the relative VOT values for the voiced and voiceless postonic stops, comparing the $\mathrm{CG}$ and DG.

Table 4. Voice Onset Time (VOT) percentage values in pretonic voiced and voiceless stops in Control Group and Deviation Group

\begin{tabular}{ccccccc}
\hline Articulation & \multicolumn{3}{c}{ voiced } & \multicolumn{3}{c}{ voiceless } \\
\cline { 2 - 6 } point & BLS & VLS & AVERAGE & BLS & VLS & AVERAGE \\
\hline CG & 12.8 & 0.1394 & 0.1389 & 2.1 & 0.0688 & 0.0402 \\
DG & 13.2 & 0.1278 & 0.1278 & 2.1 & 0.0383 & 0.02845 \\
P-value & 0.652 & 0.398 & 0.295 & 1.0 & $0.003^{*}$ & 0.131 \\
\hline
\end{tabular}

Legend: $\mathrm{CG}=$ control group; $\mathrm{DG}=$ deviation group; BLS = bilabial stop; VLS = velar stop; AVERAGE = average of values between stops; VOT in \%; significant p-value $<0.05$ (5\%) Mann-Whitney U Test and confidence interval for the median.

Table 5. Voice Onset Time (VOT) percentage values in tonic voiced and voiceless stops in Control Group and Deviation Group

\begin{tabular}{ccccccccc}
\hline $\begin{array}{c}\text { Articulation } \\
\text { point }\end{array}$ & \multicolumn{4}{c}{ voiced } & \multicolumn{4}{c}{ voiceless } \\
\cline { 2 - 9 } & BLS & AS & VLS & AVERAGE & BLS & AS & VLS & AVERAGE \\
\hline GC & 25.8 & 21.1 & 0.189 & 0.2173 & 3.8 & 4.7 & 0.1065 & 0.0570 \\
GD & 23.8 & 21.4 & 0.233 & 0.2248 & 12.0 & 2.4 & 0.0531 & 0.0288 \\
P valor & 0.208 & 0.541 & 0.472 & 0.868 & $0.014^{*}$ & 0.278 & $0.019^{*}$ & $0.006^{*}$ \\
\hline
\end{tabular}

Legend: $C G$ = control group; $D G$ = deviation group; BLS = bilabial stop; $A S=$ alveolar stop; VLS = velar stop; AVERAGE = average of values between stops; VOT in $\%$; significant $p$-value $<0.05(5 \%)$ Mann-Whitney U Test and confidence interval for the median.

Table 6. Voice Onset Time (VOT) percentage values in postonic voiced and voiceless stops in Control Group and Deviation Group

\begin{tabular}{ccccccccc}
\hline Ponto de & \multicolumn{4}{c}{ voiced } & \multicolumn{4}{c}{ voiceless } \\
\cline { 2 - 10 } articulação & BLS & AS & VLS & AVERAGE & BLS & AS & VLS & AVERAGE \\
\hline CG & 12.1 & 12.4 & 0.1039 & 0.1146 & 3.8 & 7.5 & 0.0632 & 0.0554 \\
DG & 9.6 & 14.2 & 0.11575 & 0.11575 & 2.8 & 3.8 & 0.0338 & 0.0323 \\
P-value & 0.397 & 0.962 & 0.298 & 0.846 & 0.253 & 0.129 & 0.066 & $0.006^{*}$ \\
\hline
\end{tabular}

Legend: $C G$ = control group; $D G$ = deviation group; BLS = bilabial stop; $A S=$ alveolar stop; VLS = velar stop; AVERAGE = average of values between stops; VOT in $\%$; significant p-value $<0.05(5 \%)$ Mann-Whitney U Test and confidence interval for the median.

\section{DISCUSSION}

The VOT has been indicated as an important acoustic cue in the distinctiveness between voiced and voiceless stops. Such statement has been demonstrated in phonetic studies of various languages ${ }^{6,9,14,21}$, as well as in studies on language acquisition ${ }^{2-4}$, on bilingualism and on language deviations ${ }^{15,16,22}$. This paper focused on studying VOT in stops in children with and without shifts in speech in sonority feature. The absolute duration of VOT was compared between the CG and the $D G$ in voiced and voiceless stops. The literature points to the relation of the increase in duration of VOT in voiced and voiceless stops with individuals with alterations in sonority feature ${ }^{15,22}$. in this study, the stops were analyzed according to tonicity and articulation point. Significant differences were observed in the duration of VOT between the two groups.

The analysis indicated that, in voiced pretonic stops, there was significant difference in all articulation points, as well as in the average of the sum of the stops articulation points, in which an increase in duration of VOT was observed in DG, in relation to CG (Table 1). On the 
other hand, in the voiceless pretonic stops, there was no significant difference between the groups.

In the voiced tonic stops, a significant difference was observed between the groups in velar stop and in the average of the sum of the stops articulation points, with increase in duration in DG (Table 2). In the voiceless tonic stops, the result was repeated, though with decrease of VOT in DG.

Analyzing another variable, it is observed that in voiced postonic stops, as well as in the tonics, a significant differences were found in velars and in the average of the sum of the stops articulation points (Table 3).

As for the voiceless, there was no significant difference between the groups. The results agree with studies regarding VOT of voiced stops ${ }^{14,15}$. The authors indicated increase in VOT in individuals with shift in sonority feature. In this study, this increase took place in all tonicity contexts, as well as in the average of the sum of articulation points, with prevalence for the velar stop. The results seem to point to VOT as an element in the distinctiveness mark between voiced and voiceless phonemes.

It is important to highlight that, in the case of individuals with shifts in speech involving voicing, there seems to be an attempt to mark voicing by prolonging the VOT. Thus, it can be supposed that this voicing cue can be used in speech-language-hearing therapy to increase the individual's perception with language deviation. It is noted that some patients, in spite of desonorization in emitting phonemes, recognize the difference between [faca] $\times$ [vaca], for instance; whereas others are incapable of making such distinction. Based on this study's findings, it is believed that, in speech-language-hearing practice, the exercises for sound discrimination of suprasegmental features may be associated with the work of discriminating the voicing feature. One suggestion would be the auditory training with exercises for the perception and imitation of suprasegmental features with longshort stimuli.

As for the voiceless stops VOT, there was significant difference between the groups only in the tonic context, with decrease in VOT in the deviation group. Other studies ${ }^{15,16}$ did not find significant differences in the groups studies, even though they had analyzed the same phonetic context ${ }^{14}$.

Concerning the relative duration of VOT, there was no significant difference between the groups in voiced stops in no phonetic context (Tables 4, 5 and
6). However, there was a tendency to increase in VOT value in the DG in relation to the CG. This same result appeared in the analysis of absolute duration of VOT, and was in agreement with other papers involving absolute duration of $\mathrm{VOT}^{15,16}$. The relative VOT of voiced stops in different age groups $(6,8,10$, 12 years) of speakers without alterations in speech was compared, and the results indicated significant differences between the groups for the segment [b] and edge significant differences for [g] ${ }^{14}$.It can be supposed that the nonequivalence of the results in this paper with the one cited may have occurred for the comparison having been made with children of different age groups, without alterations in speech.

As for voiceless stops, there was a significant difference between the groups in all phonetic contexts, being in the average of the sum of articulation points of the tonic and postonic stops, and in pretonic and tonic velar stops. Just as in the absolute VOT of voiceless stops, there was a reduction of relative VOT of the DG in relation to the CG. The relative VOT of voiceless stops of speakers without alterations in speech was compared, and no statistically significant results were found between the age groups, except for the segment[p], comparing the 6- and 8-year-old groups to the adult group ${ }^{14}$. The author suggests that caution be taken in the analysis of the results, once in absolute form the voiceless stops presented statistical differences between each other. Once again, the results of this study do not agree with the cited research. Nevertheless, they reinforce the findings in the absolute VOT of voiceless stops.

The abovementioned data seem to reinforce the difference in VOT in the groups studied, both in absolute and relative duration, though the utterance rate, represented by the relative VOT, did not present consistent results throughout the analysis.

\section{CONCLUSION}

The results point to a specific acoustic pattern of distinctiveness in children with alterations in their sonority feature in relation to other speakers of the language. The results of absolute VOT measurements have shown to be sturdier than those of the relative VOT in the comparison between the analyzed groups. 


\section{REFERENCES}

1. Saffran JR, Aslin RN, Newport EL. Statistical learning by 8-month-old infants. Science. 1996;274(5294):1926-8.

2. Eimas PD. The perception of speech in early Infancy. Scientific American. 1985;252(1):46-52.

3. Eimas PD, Siqueland E, Jusczyk $P$, Vigorito J. Speech perception in infants. Science.1971;171(3968):303-6.

4. Hale M, Kissock M. Perception of non-native phonological contrasts: evidence from and for featural representations. Fifteenth Manchester Phonology Meeting; 2007 May 24-26, Manchester.

5. Werker JF, Tees RC. Cross-language speech perception: evidence for perceptual reorganization during the first year of life. Infant behav dev.1984;7(1):49-63.

6. Lisker L, Abramson AS. A cross-language study of voicing in initial stops: acoustical measurements. WORD. 1964;20(3):384-422.

7. Lofredo-Bonatto MTR. Vozes infantis: a caracterização do contraste de vozeamento das consoantes plosivas no português brasileiro na fala de crianças de 3 a 12 anos [tese]. São Paulo (SP): Pontifícia Universidade Católica; 2007.

8. Fátima MD, Oliveira M, Lousada M, Jesus LMT. Análise temporal das oclusivas orais do português europeu: um estudo de caso de normalidade e perturbação fonológica. Rev. CEFAC. 2007;9(2):154-63.

9. Ladefoged $P$, Johnson $K$. A course in phonetics. Stamford: Cengage Learning; 2014.

10. Chodroff E, Wilson C. Burst spectrum as a cue for the stop voicing contrast in American English. J Acoust Soc Am. 2014;136(5):2762-72.

11. Cho $T$, Ladefoged $P$. Variation and universals in VOT: evidence from 18 languages. JP. 1999;27(2):207-29.

12. Leite AF, Silva SB, Oliveira e Britto ATB, Di Ninno CQMS. Lisp characterization of patients from the Centro Clínico de Fonoaudiologia. Rev. soc. bras. fonoaudiol. 2008;13(1):30-6.

13. Cristofolini C, Seara IC. Características acústicas de consoantes plosivas e fricativas produzidas por crianças de 6 e 12 anos: período de refinamento articulatório? Verba volant. 2012;3(1):55-71.

14. Cristofolini C. Gradiência na fala infantil: caracterização acústica de segmentos plosivos e fricativos e evidências de um período de refinamento articulatório [tese]. Florianópolis (SC): Universidade Federal de Santa Catarina; 2013.

15. Britto AT. O estudo do contraste do vozeamento em sujeitos com e sem desvio fonológico. [tese] Belo Horizonte (MG): Pontifícia Universidade Católica; 2010.

16. Mota HB, Paula A, Mezzomo CL. Mudanças fonológicas na terapia de sujeitos com desvio fonológico utilizando "contraste" e "reforço" do traço [voz]. Letras de hoje. 2008;43(3):7-14.

17. Melo RM, Mota HB, Mezzomo CL, Brasil BC, Lovatto L, Arzeno L. Parâmetros acústicos do contraste de sonoridade das plosivas no desenvolvimento fonológico típico e no desviante. Rev. soc. bras. fonoaudiol. 2012;17(3):304-12.

18. Wertzner HF. Fonologia. In: Andrade CRF (org). ABFW - Teste de linguagem infantil nas áreas de fonologia, vocabulário, fluência e pragmática. São Paulo: Pró-Fono; 2006. p.5-40.

19. Ramone L. Nativos entre nativos: especializações acústicas de falantes com trocas no traço de sonoridade [tese]. Rio de Janeiro (RJ): Universidade Federal do Rio de Janeiro; 2014.

20. Random.org. [homepage na Internet] RandomIntegerGenerator [acesso em 2013 ago 20]. Disponível em: http://www.random.org/ integers/.

21. Ladefoged $P$, Cho $T$. Linking linguistic contrasts to reality: The case of VOT. UCLA: WPP. 2000;XXXI(1954):212-25.

22. Cristofolini C. Trocas ortográficas: uma interpretação a partir de análise acústica [Dissertação]. Florianópolis (SC): Universidade Federal de Santa Catarina; 2008. 